Supplement of Atmos. Chem. Phys., 17, 2311-2346, 2017

http://www.atmos-chem-phys.net/17/2311/2017/

doi:10.5194/acp-17-2311-2017-supplement

(C) Author(s) 2017. CC Attribution 3.0 License.

(c) (i)

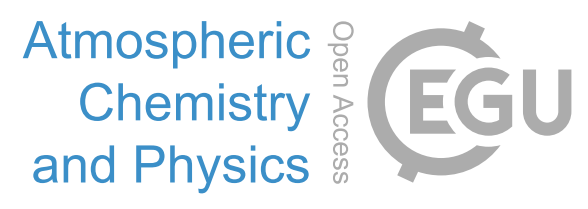

Supplement of

\title{
Long-lived contrails and convective cirrus above the tropical tropopause
}

Ulrich Schumann et al.

Correspondence to: Ulrich Schumann (ulrich.schumann@ dlr.de)

The copyright of individual parts of the supplement might differ from the CC-BY 3.0 licence. 


\section{Content}

Addition to 2.3: Test of the plume detection method for flight during TROCCINOX, SCOUT-O3, and RECONCILE...........2

Addition to 3.1: Coordinates of Geophysica and Falcon flights during the photo observation of the contrail of 16 November

2005

10 Addition to 3.1: Further photos, similar to Figure 1, at other times of 16 November 2005



Addition to 3.2: Further measurement results versus time for the time period containing of events.................................. 7

Addition to 3.2: Further event identification from correlation analysis........................................................................ 10

Addition to 3.2: Falcon lidar backscatter result for the whole flight period

Addition to 3.2: CPOL radar reflectivity $\mathrm{Z}$ along the Geophysica flight path for various altitude and times of 30 November 2005

Addition to 3.2: NOAA-AVHRR satellite at 5:15:43 UTC 30 November 2005.

Addition to 4.5: Order of magnitude estimates for contrail parameters for 16 November 2005 
Addition to 2.3: Test of the plume detection method for flight during TROCCINOX, SCOUT-O3, and RECONCILE.

Table S1. Test results of the plume detection method for observed aerosol peak events.

Several aerosol peaks have been measured with COPAS during TROCCINOX, SCOUT-O3, and RECONCILE. Some of these peaks were previously named "features" and numbered F1.1 to F1.2 for flight 5 February 2005 of TROCCINOX and

5 F2.1 to F2.3 for flight 25 November 2005 of SCOUT-O3 (Weigel et al., 2009). Here we consider a further feature F2.4 with a peak in the measured aerosol concentrations at time $20365 \mathrm{~s}$ during the flight of 25 November 2005. In addition, we consider three COPAS-measured events "R25.1, R30.1 and R30.2" for the flights of 25 and 30 January 2010 during RECONCILE (Sumińska-Ebersoldt et al., 2012). For all these events, the plume detection method described in Section 2.3 (inner loop only) is applied to find properties of the potential plumes that might explain the aerosol peaks measured at time $\mathrm{t}$ $=t_{2}$. For each event, the following table lists the project name, flight day, plume age, time of event after midnight, and differences $(\Delta \mathrm{z}, \Delta \mathrm{u}, \Delta \mathrm{v}, \Delta \mathrm{w}, \Delta \theta)$ in vertical position, velocity components and potential temperature between observed and predicted positions, computed for assumed primary or secondary wake behavior (p or $\mathrm{s}$ ) and for the measured wind (based on TDC data). The time difference $t_{2}-t_{1}$ is the plume age, and the corresponding emission position could be that at time $t_{1}=$ $t_{2}$ - age in the flight path data. The results show that the aerosol peaks for 8 of 9 events can reasonably be explained as aircraft exhaust plumes, based on this analysis, with small deviations $(\Delta \mathrm{z}, \Delta \mathrm{u}, \Delta \mathrm{v}, \Delta \mathrm{w}, \Delta \theta)$. Also for feature F1.1 during TROCCINOX, high aerosol peaks were observed (Weigel et al., 2009), and the plume detection method finds a plume that potentially could explain this feature, but with large $\Delta z$ and $\Delta \theta$ changes. This suggests that this observed feature cannot be explained by plume encounters and the measured wind for this cases; either the wind was more variable or the aerosol peak has other reasons (Nielsen et al., 2007). Hence, the plume detection method has been tested successfully for plume encounters with plume ages up to $2.2 \mathrm{~h}$, with the TROCCINOX feature F1.2 being the one with highest age. Still this limit may be incidental because it depends on the actual wind and on the true cause for the features that were observed.

\begin{tabular}{|c|c|c|c|c|c|c|c|c|c|c|c|}
\hline Project & $\begin{array}{l}\text { Date (day. } \\
\text { month.year) }\end{array}$ & Event & Age/s & $t / s$ & $\mathrm{z} / \mathrm{km}$ & $\Delta \mathrm{z} / \mathrm{m}$ & $\begin{array}{l}\Delta \mathrm{u} / \\
\left(\mathrm{m} \mathrm{s}^{-1}\right)\end{array}$ & $\begin{array}{l}\Delta \mathrm{v} / \\
\left(\mathrm{m} \mathrm{s}^{-1}\right)\end{array}$ & $\begin{array}{l}\Delta \mathrm{w} / \\
\left(\mathrm{m} \mathrm{s}^{-1}\right)\end{array}$ & $\Delta \theta / \mathrm{K}$ & $\mathrm{p}, \mathrm{s}$ \\
\hline TROCCINOX & 05.02 .2005 & F1.1 & 2535 & 64046 & 17.42 & -823 & 0.11 & -0.85 & -0.28 & -21.78 & $\mathrm{~s}$ \\
\hline TROCCINOX & 05.02 .2005 & F1.2 & 7958 & 63012 & 16.51 & -108 & 0.04 & 0.02 & 0.01 & -2.35 & $\mathrm{~s}$ \\
\hline SCOUT-O3 & 25.11 .2005 & F2.1 & 579 & 14955 & 17.52 & 6 & -0.40 & -0.72 & 0.02 & -0.19 & $\mathrm{p}$ \\
\hline SCOUT-O3 & 25.11 .2005 & $\mathrm{~F} 2.2$ & 601 & 25431 & 18.24 & -173 & -0.54 & -0.26 & 0.01 & -1.76 & $\mathrm{p}$ \\
\hline SCOUT-O3 & 25.11 .2005 & F2.3 & 1280 & 14621 & 17.56 & 32 & -0.20 & -0.21 & 0.03 & 0.23 & $\mathrm{p}$ \\
\hline SCOUT-O3 & 25.11 .2005 & F 2.4 & 1444 & 20365 & 16.82 & 5 & 0.04 & 0.13 & 0.01 & -0.81 & $\mathrm{~s}$ \\
\hline RECONCILE & 25.01 .2010 & R25.1 & 1802 & 25715 & 18.13 & 1 & -1.88 & -2.52 & 0.00 & -1.21 & $\mathrm{~s}$ \\
\hline RECONCILE & 30.01 .2010 & R30.1 & 1022 & 29484 & 17.78 & -10 & -0.69 & -5.68 & -0.03 & -0.06 & $\mathrm{~s}$ \\
\hline RECONCILE & 30.01 .2010 & $\mathrm{R} 30.2$ & 1218 & 29390 & 17.78 & 5 & -0.01 & -3.74 & 0.01 & 0.78 & $\mathrm{~s}$ \\
\hline
\end{tabular}


Addition to 3.1: Coordinates of Geophysica and Falcon flights during the photo observation of the contrail of 16 November 2005

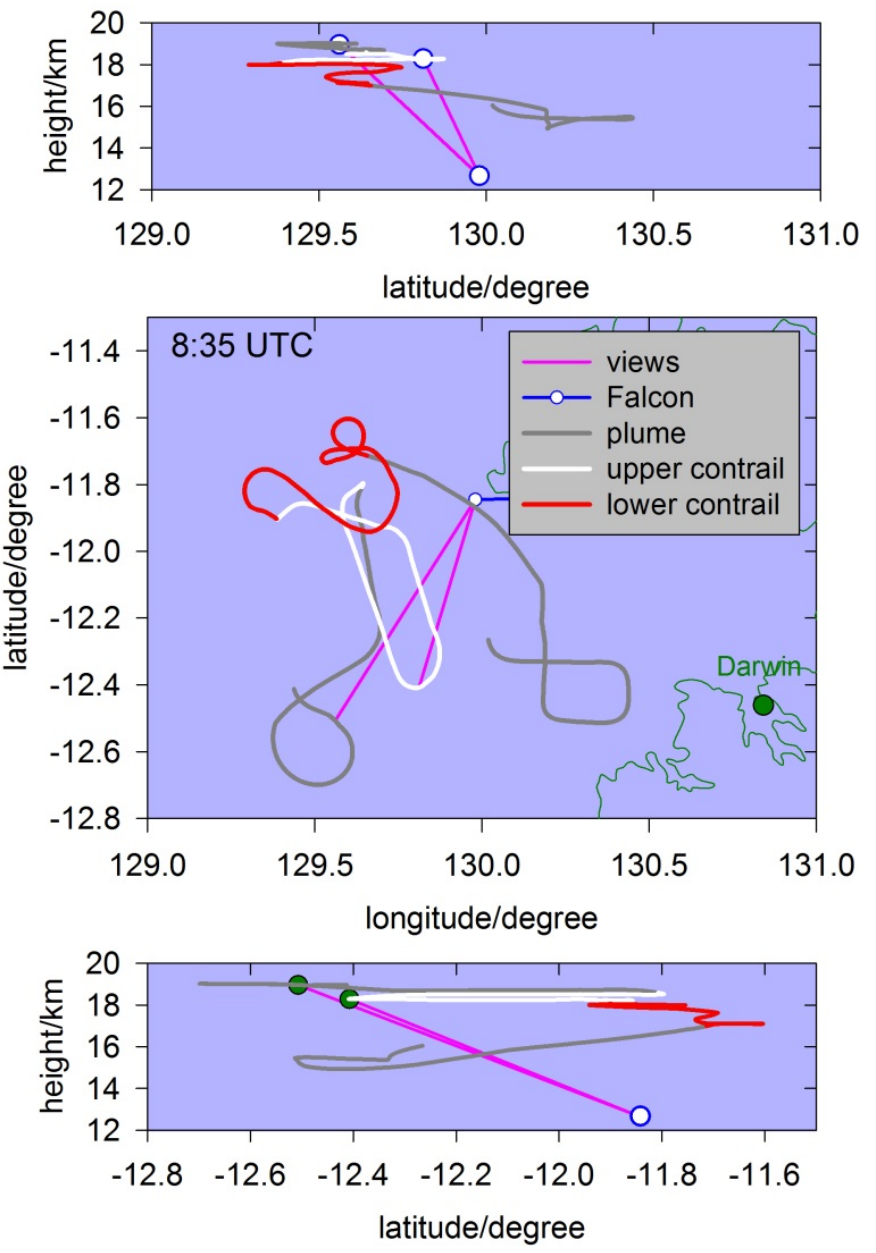

Figure S1. Coordinates of the Geophysica-exhaust plume and the Falcon flight part in the time until 8:35 UTC 16 November

5 2005, when the photo of Figure 1 was taken, versus height and longitude (top), latitude and longitude both (middle), and height and latitude (bottom). The blue symbols depict the Falcon position at the time of the photo. The grey line is the computed position of the exhaust plume at the time of the photo. The white and red parts of the exhaust plume are the upper and lower contrails seen in Figures 1 to 3. The green symbol is the positon of the Darwin airport. The purple line is the view from the Falcon to two arbitrarily selected points along the computed plumes, one in the "invisible" plume and one in the upper contrail. Note that the invisible plume, though at higher altitudes, appears below the upper contrail part, both in view directions perpendicular to the longitude and to latitude axes and, hence, also in the photo perspective. 
Addition to 3.1: Further photos, similar to Figure 1, at other times of 16 November 2005.

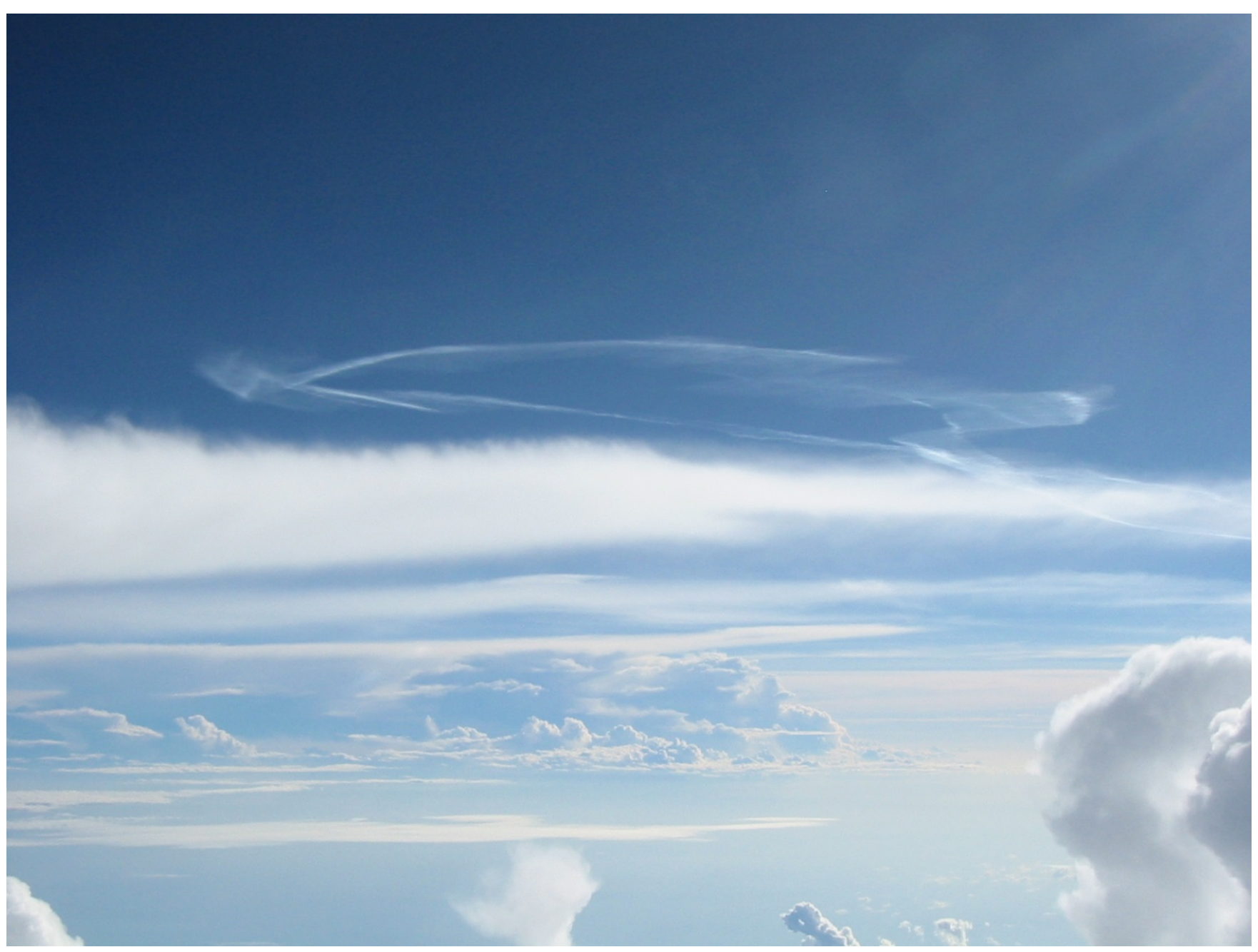

Figure S2. Geophysica contrail, photo from the DLR Falcon at 8:34:54 UTC 16 November 2005. 


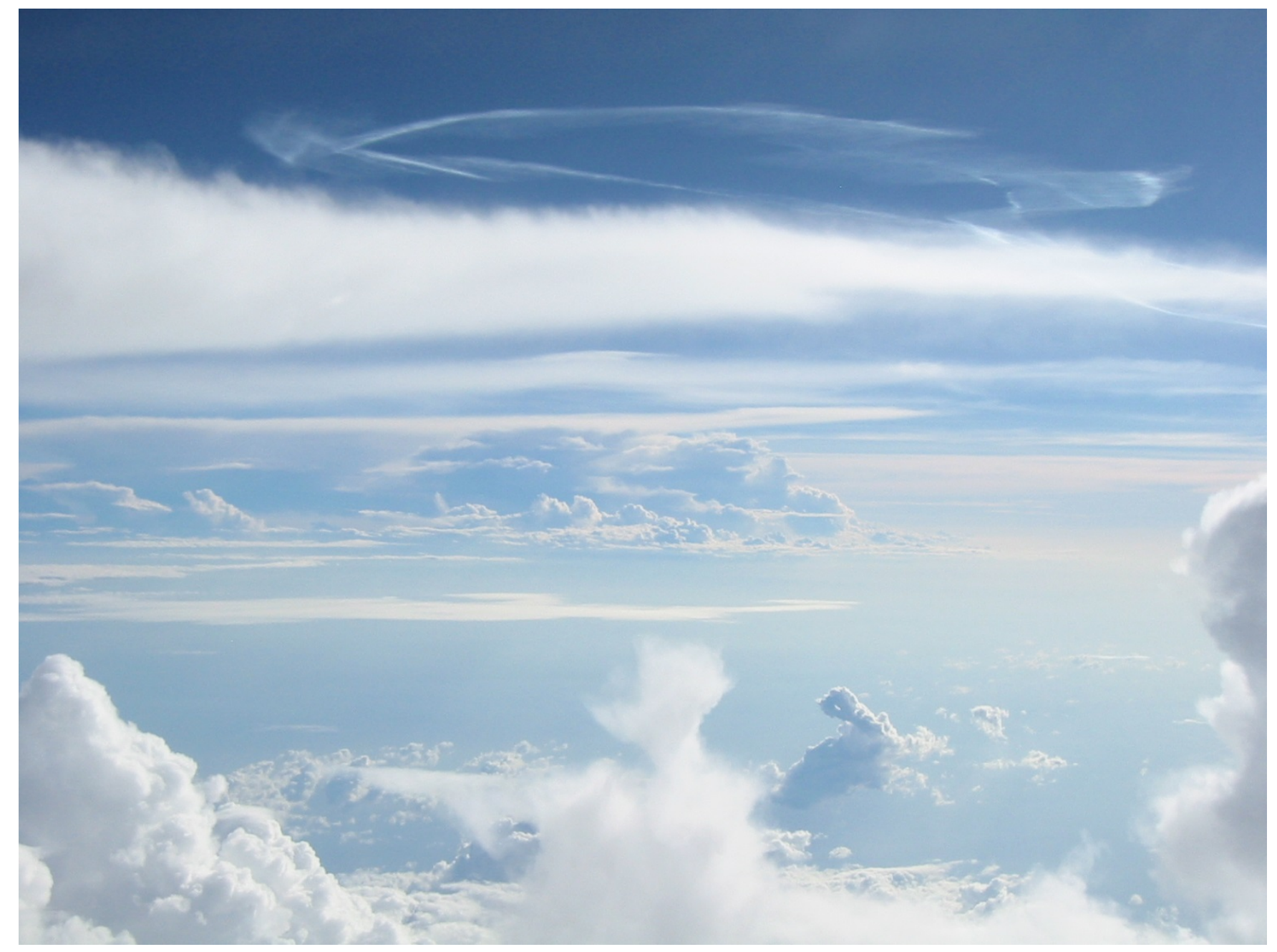

Figure S3. Geophysica contrail, photo from the DLR Falcon at 8:35:02 UTC 16 November 2005. 

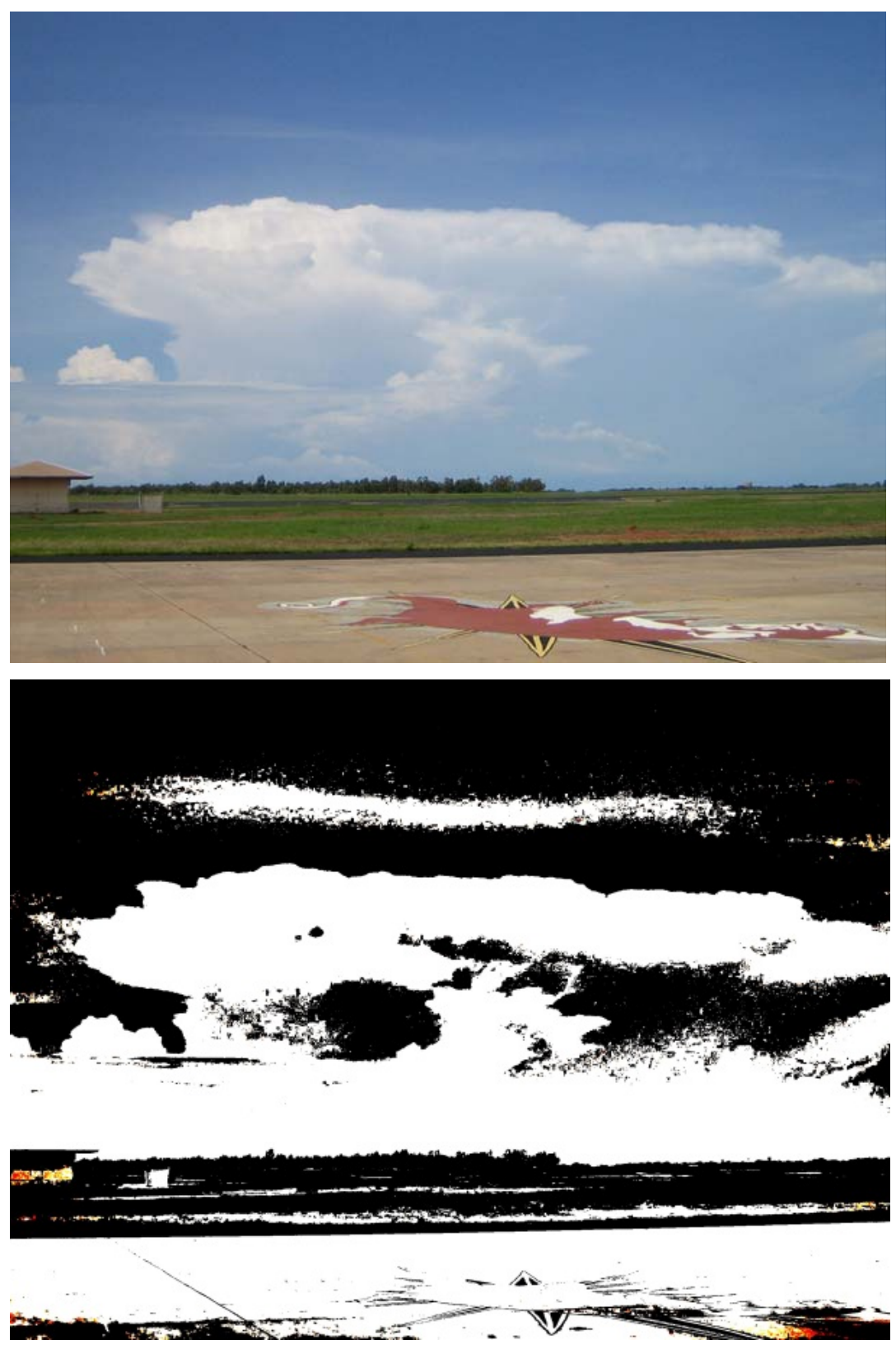

5 Figure S4. Top: Photo of Hector over Tiwi Island with thin tropopause cirrus taken from Darwin airport $\left(130^{\circ} 53^{\prime} \mathrm{E}, 12^{\circ} 25^{\prime} \mathrm{S}\right)$ at 5:01 UTC 30 November 2005. Bottom: Contrast-enhanced black/white version of the same photo, identifying a thin but wide layer of subvisible clouds near the top of the photo, in which the Geophysica flew at about $15 \mathrm{~km}$ altitude from west to east south of the Tiwi Islands, south of Hector (see grey part of flight path near $12^{\circ} \mathrm{S}$ in Figure 7) shortly before the time of the photo. The contrail itself cannot be distinguished from the pre-existing thin cirrus in this photo. 
Addition to 3.2: Further measurement results versus time for the time period containing of events

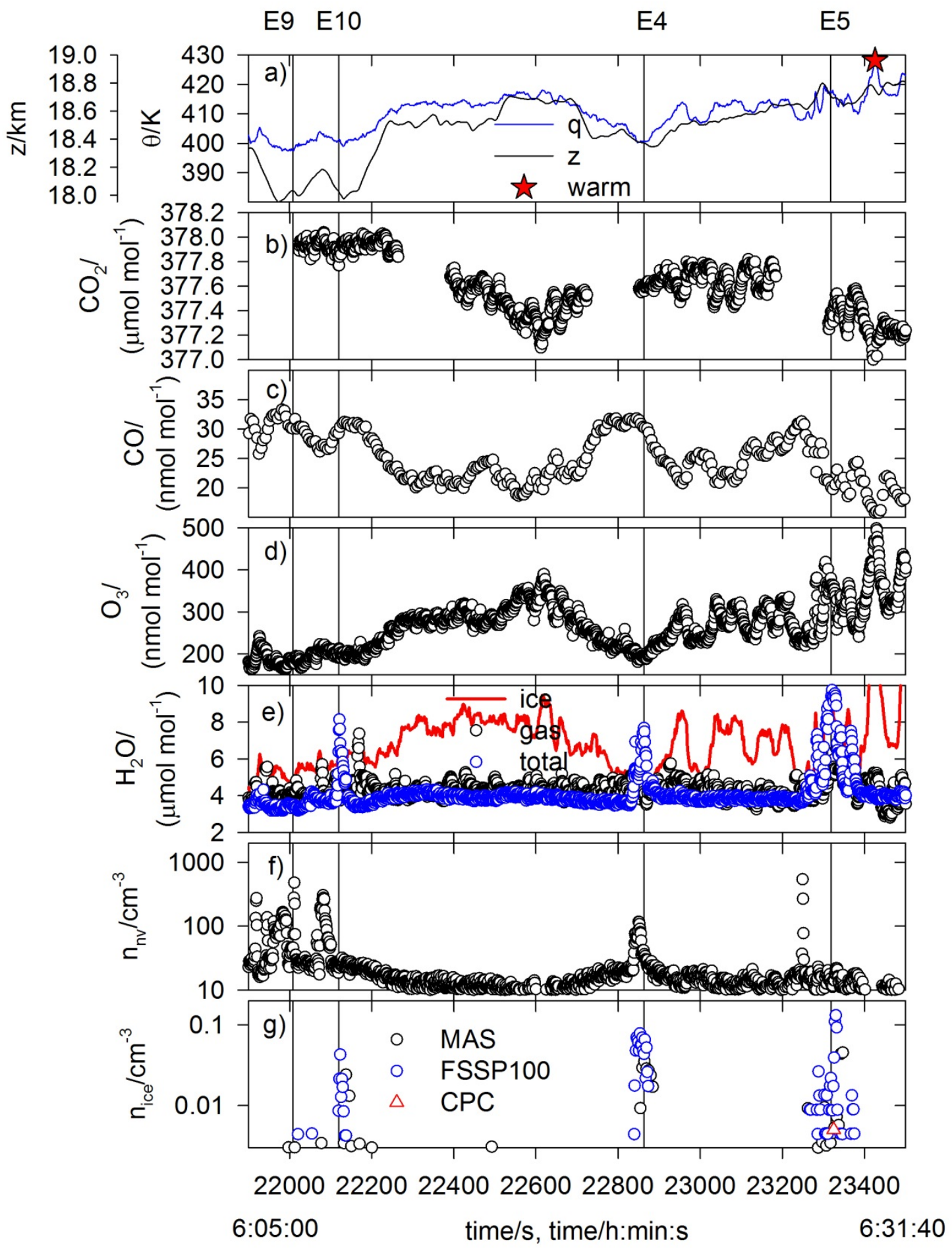


Figure S5. Measurement results versus time for the time period of 30 November 2005 containing events E9, E10, E4 and E5 (with event times indicated by vertical lines; see Table 4. a) $1-\mathrm{Hz}$ data for altitude $\mathrm{z}$ and potential temperature $\theta$, with identification of the point of maximum temperature ("warm"). b) Molar mixing ratios of carbon dioxide $\mathrm{CO}_{2}$, c) carbon monoxide $\mathrm{CO}$, d) ozone $\mathrm{O}_{3}$, e) water vapor $\mathrm{H}_{2} \mathrm{O}$, for ice saturation (red line), gas phase (black circle), total (blue circle). f)

5 Nonvolatile particle concentration $n_{n v}$ and $g$ ) ice particle concentrations $n_{\text {ice }}$ as derived from MAS backscatter (black), FSSP100 (blue) and CIP (red). 
E11 E12 E13 E6

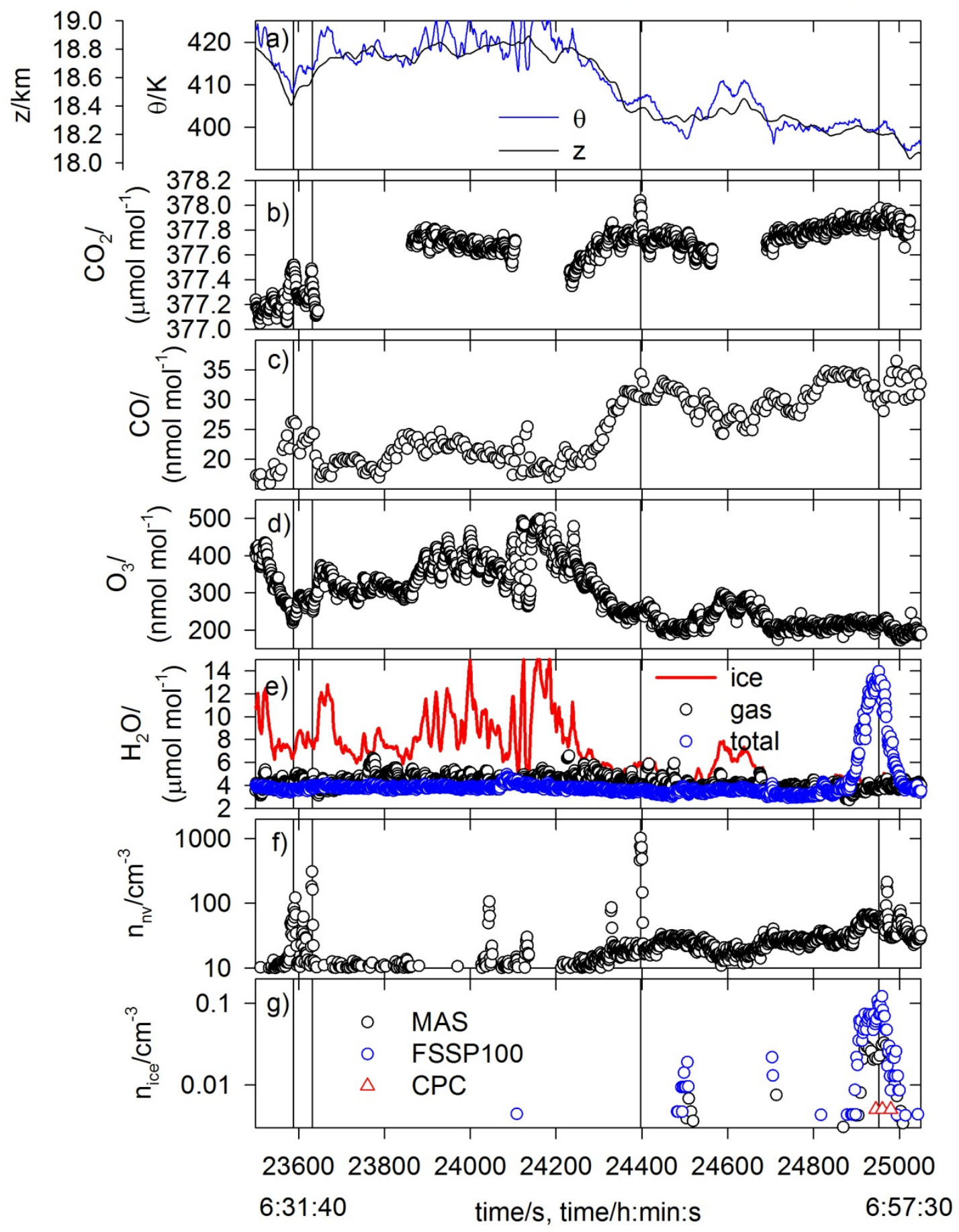

Figure S6. Same for E11, E12, E13 and E6. 

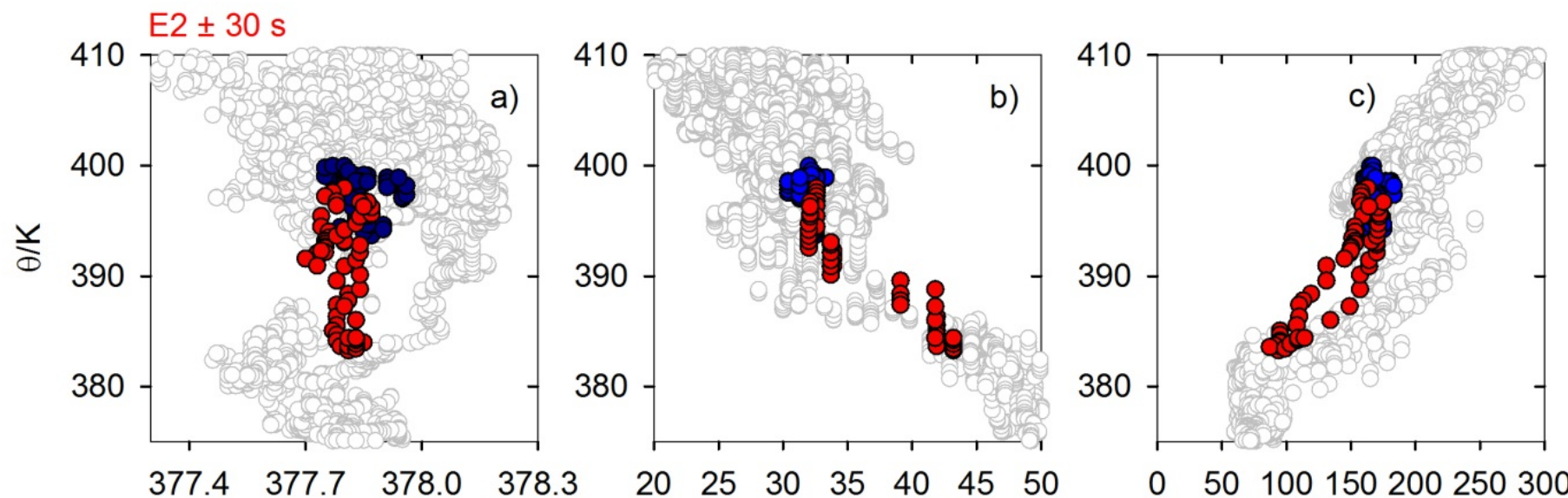

$\begin{array}{llll}377.4 & 377.7 & 378.0 & 378.3\end{array}$ $\mathrm{CO}_{2} /\left(\mu \mathrm{mol} \mathrm{mol}{ }^{-1}\right)$

$\mathrm{CO} /\left(\mathrm{nmol} \mathrm{mol}{ }^{-1}\right)$
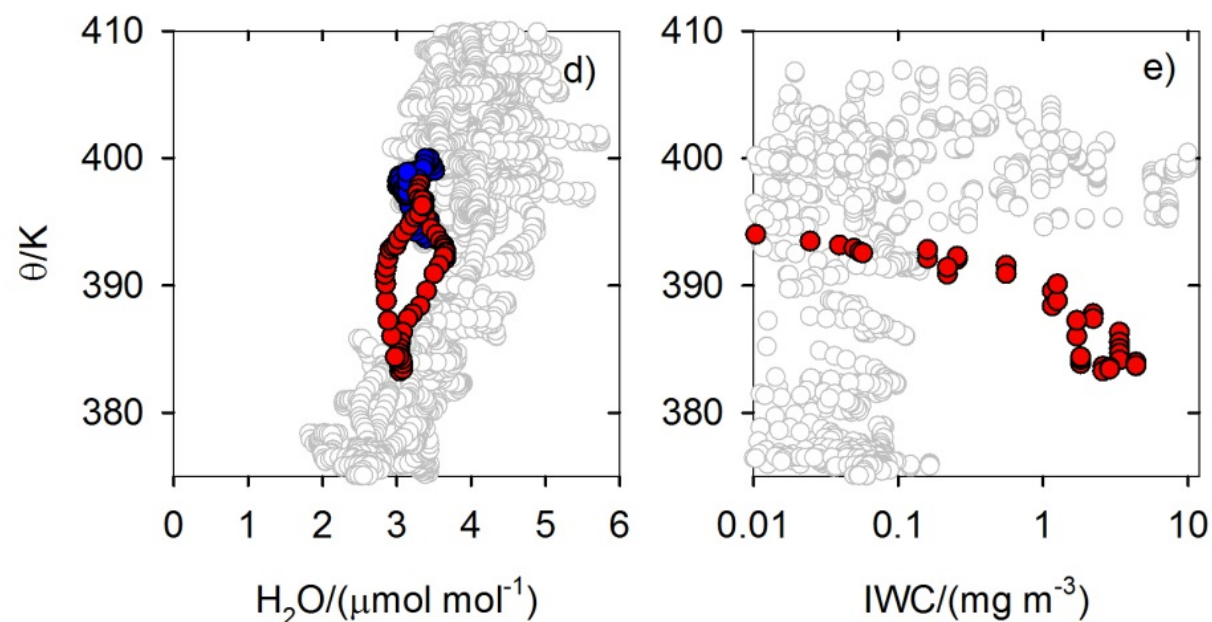
$\left.\mathrm{O}_{3} /(\mathrm{nmol} \mathrm{mol})^{-1}\right)$

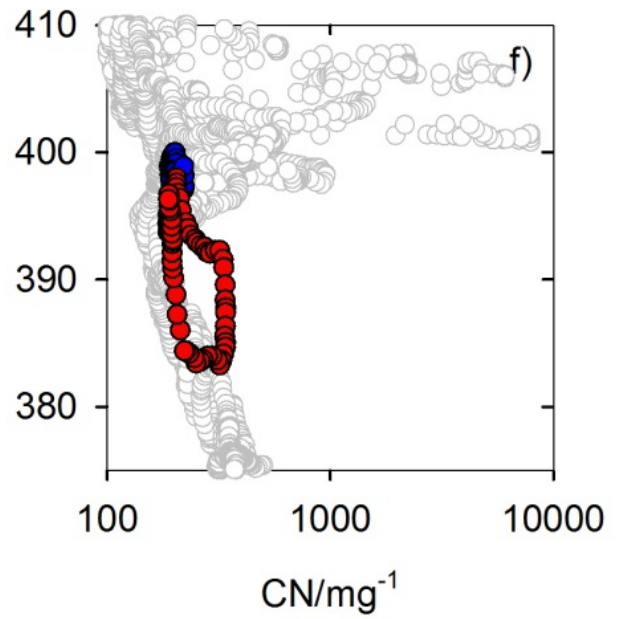

Figure S7. Case E2, best example for convective induced ice event of 30 November 2005. Same data as in Figure 9. Grey: all data. Red: data within $\pm 30 \mathrm{~s}$ before and after $\mathrm{t}=20600$, blue: neighbors in the next 30 -s intervals before and after this 5 interval. Data with $1 \mathrm{~Hz}$ resolution. 
Addition to 3.2: Falcon lidar backscatter result for the whole flight period
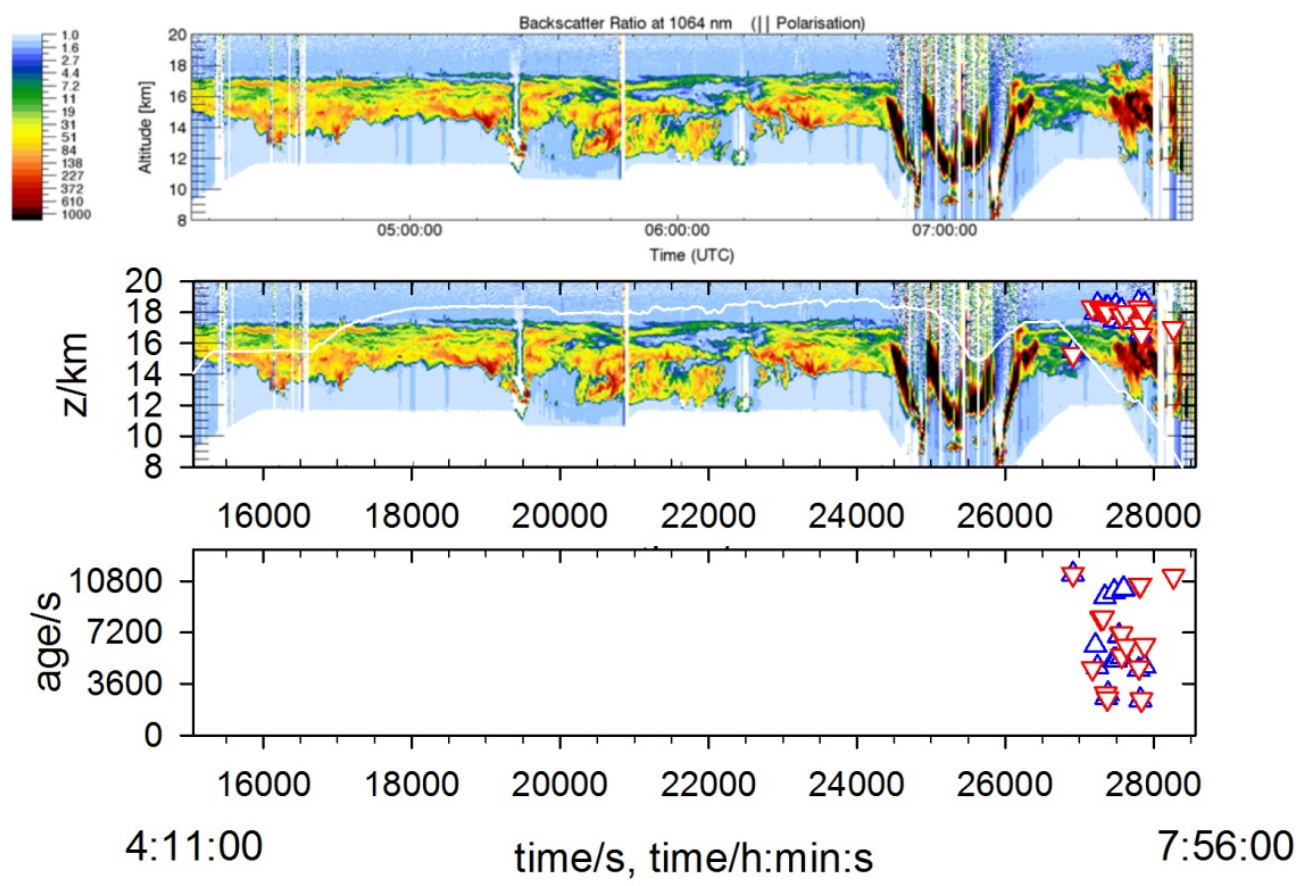

Figure S8. Falcon lidar 1064-nm backscatter in the vertical plane ("curtain") above the flight level during the 4-h morning flight of 30 November 2005. Middle: Same lidar result with overlay of potential contrail positions in time and altitude, for 5 primary wakes (red symbol) and secondary wakes (blue symbol). The thin white line denotes the Geophysica altitude at the same time. Bottom: Corresponding plume ages at the lidar observation time. 
Addition to 3.2: CPOL radar reflectivity $\mathrm{Z}$ along the Geophysica flight path for various altitude and times of 30 November 2005

CPOL radar reflectivity Z in horizontal cross-sections and in "curtains" along the Geophysica flight path for various altitude and times, also including the Falcon flight path (324 images, 205 MByte data set size), are available as a compressed file 5 (133 MByte) in CPOL_HECTOR_30Nov2005_a.zip at BOM ftp (see paper).

The figures are available every $10 \mathrm{~min}$ from 3 to 9 UTC, 30 November 2005, and in $1 \mathrm{~km}$ steps from 12 to $20 \mathrm{~km}$ altitude above MSL. The figures are centered on the UTC times and altitudes above MSL as given in the plots and in the file names.

Occasionally the radar measured reflection from the Geophysica aircraft, as can be seen from artificial reflectivities at

10 flight altitude on the vertical cross-sections. The value of reflectivity changes with the location of the aircraft inside the radar beam, with stronger reflectivities when the aircraft is in the center of the beam.

Approximate times and reflectivity levels when CPOL measured reflection from the Geophysica aircraft are:

- $\quad 0435$ CPOL image: $t$ (Geophysica) 16500-16550 s (15-20 dBZ)

- 0555 CPOL image: $t$ (Geophysica) 21360-21400 s (30-35 dBZ)

- $\quad 0615$ CPOL image: $t$ (Geophysica) 22500-22550 s (15-20 dBZ)

- 0705 CPOL image: $\mathrm{t}$ (Geophysica) 25670-25700 s (25-30 dBZ)

- 0735 CPOL image: $t$ (Geophysica) 27180-27220 s (20-30 dBZ)

- $\quad 0745$ CPOL image: $t$ (Geophysica) 27910-27950 s (15-20 dBZ) Branch, Melbourne, Victoria, Australia. 
Addition to 3.2: NOAA-AVHRR satellite at 5:15:43 UTC 30 November 2005.
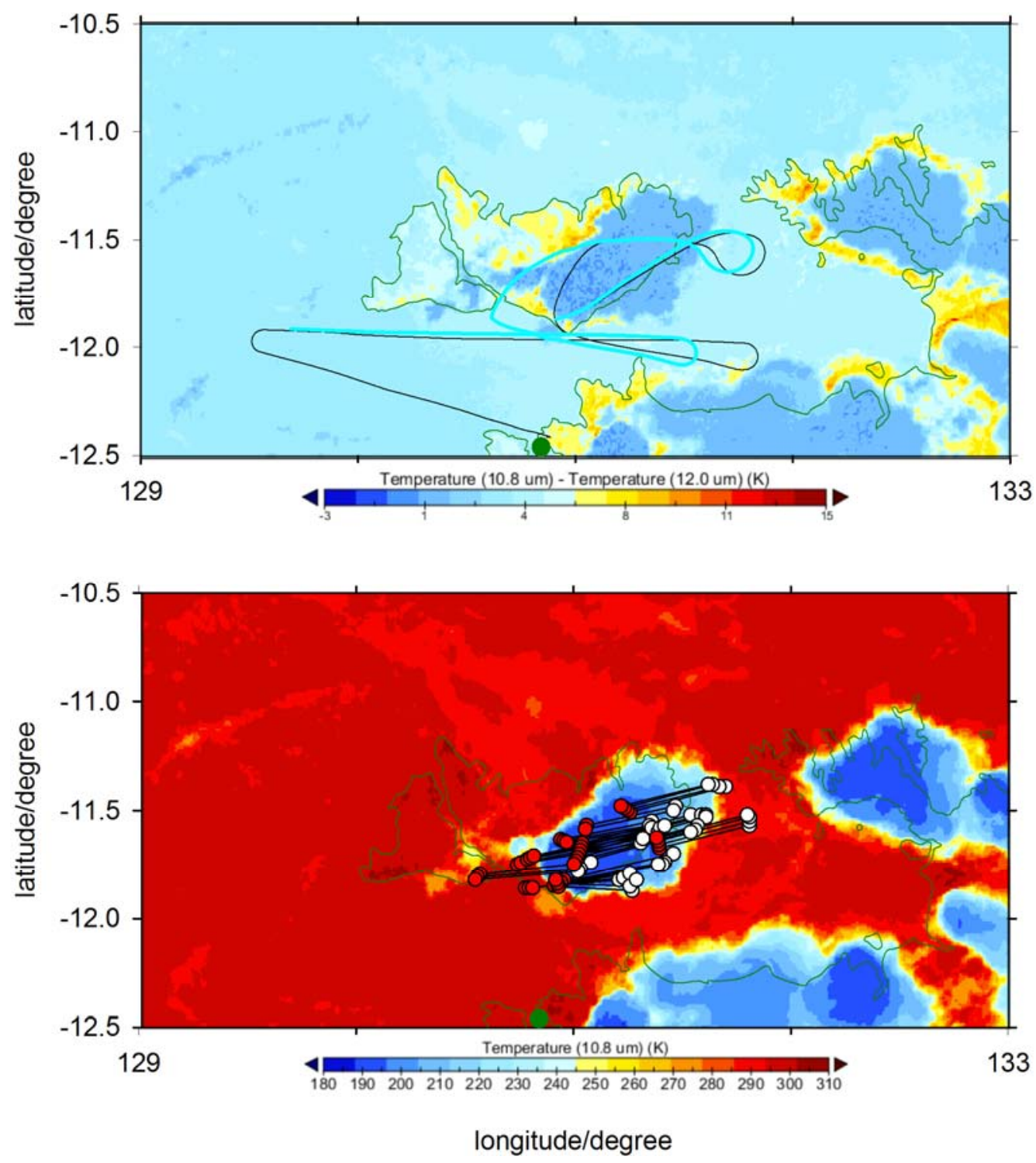

Figure S9. Brightness temperature (BT, bottom, at 10.8- $\mu \mathrm{m}$ wavelength) and BT difference (BTD, top; difference between BT at 10.8 and $12 \mu \mathrm{m}$ ) from 1-km resolution NOAA-18 AVHRR, at 5:15:43 UTC 30 November 2005. Darwin is indicated 5 by a green symbol and the coast by a green line. Top: The black curve is the Geophysica flight path. The cyan curve is the computed position of the contrail for ages $<1 \mathrm{~h}$ at the time of the overpass. Bottom: Black lines represent backward trajectories from points with high nv particle concentration (red circles) to the places (white circles) of the same air mass at 3 UTC (12:30 LT), i.e., at a time before convection started, indicating that the convective tower east of Hector is not the cause for the high particle concentrations measured over Hector. 
Addition to 4.5: Order of magnitude estimates for contrail parameters for 16 November 2005

Here we estimate the mean particle sizes $r$, the particle concentration $n_{\text {ice }}$ per volume, and the optical depth $\tau$ of the stratospheric contrails with parameters as given in Section 3.1. The model used is similar to that used in CoCiP (Schumann, 2012), which results have been shown to provide reasonable approximations to observations (Jeßberger et al., 2013;

5 Schumann et al., 2017; Schumann and Heymsfield, 2017).

The equations used represent mean values in the contrail cross-section A. Real contrails contain a spectrum of ice particles of various sizes and of various habits, and this is important because smaller ice particles sublimate more quickly than larger ones, in particular, at the contrail boundary in ice-subsaturated air because of lowest relative humidity and in the interior of the contrail because of turbulent humidity fluctuations and the Kelvin effect (Lewellen, 2014). However, here we present order-of-magnitude estimates. Moreover, we assume unimodal spherical ice particles, for which the volume, area and effective radius values are equal, $r=r_{v o l}=r_{\text {area }}=r_{\text {eff }}$. For radius definitions see Schumann et al. (2011).

The optical depth of a contrail,

$\tau=\pi r^{2} n_{\text {ice }} D_{\text {eff }} Q_{\text {ext }}(r)$,

is a function of the particle cross-section $\pi r_{\text {area }}{ }^{2}$, the number of ice particles per volume $n_{\text {ice, }}$, the effective vertical geometrical contrail depth $\mathrm{D}_{\text {eff }}$ and $\mathrm{Q}_{\mathrm{ext}}$. The radiation extinction efficiency $\mathrm{Q}_{\mathrm{ext}}$ is a function of particle radius $\mathrm{r}$ according to approximate Mie-theory,

$\mathrm{Q}_{\mathrm{ext}}=2-\left(4 / \rho_{\lambda}\right)\left(\sin \left(\rho_{\lambda}\right)-\left(1-\cos \left(\rho_{\lambda}\right)\right) / \rho_{\lambda}\right.$

with $\rho_{\lambda}=4 \pi \mathrm{r}(\kappa-1) / \lambda, \kappa=1.31$ as the real refractive index of ice, and $\lambda=550 \mathrm{~nm}$ the wavelength of visible light (van de Hulst, 1957).

20 The mean particle concentration $n_{\text {ice }}$ equals the total number of ice particles per flight distance $\mathrm{N}_{\text {ice }}$ divided by the contrail cross-section area $\mathrm{A}$,

$\mathrm{n}_{\text {ice }}=\mathrm{N}_{\text {ice }} / \mathrm{A}$.

The $\mathrm{N}_{\mathrm{ice}}$ can be expressed as the product of the apparent emission index of ice particles forming in the contrail, $\mathrm{PEI}_{\mathrm{ice}}$, times the fuel mass consumption $\mathrm{m}_{\mathrm{F}}$ per flight distance:

25 Nice $=$ PEI $_{\text {ice }} \mathrm{m}_{\mathrm{F}}$.

The cross-section area $\mathrm{A}$ is a function of fuel consumption $\mathrm{m}_{\mathrm{F}}$ per flight distance, air density $\rho$, and dilution $\mathrm{N}_{\mathrm{dil}}$ : $\mathrm{A}=\mathrm{N}_{\mathrm{dil}} \mathrm{m}_{\mathrm{F}} / \rho$.

The area A equals the contrail width $\mathrm{W}$ times the effective depth $\mathrm{D}_{\text {eff }}$ (which defines $\mathrm{D}_{\text {eff }}$ ), $\mathrm{A}=\mathrm{W} \mathrm{D}_{\text {eff. }}$.

30 The width $\mathrm{W}$ can be prescribed or can be calculated as a function of wing span s, time $\mathrm{t}$, shear $\mathrm{S}$, and vertical wake vortex depth $D: W(t)=\max (s, D S t)$. The wake depth is $D=w_{0} \min \left(t, t_{w a k e}\right)$, where $w_{0}$ is the wake vortex descent velocity and $t_{\text {wake }}$ the maximum wake vortex descent time (Paoli and Shariff, 2016), see Section 2. Hence, $\tau=\pi r^{2}\left(\mathrm{PEI}_{\text {ice }} \mathrm{m}_{\mathrm{F}} / \mathrm{W}\right) \mathrm{Q}_{\mathrm{ext}}(\mathrm{r})$ 
The mean particle size is a function of ice water content IWC, ice bulk density $\rho_{\text {ice }}$ and ice particle concentration $\mathrm{n}_{\text {ice }}$, $\mathrm{r} \cong \mathrm{r}_{\mathrm{vol}}=\left[\operatorname{IWC} /\left(\rho_{\text {ice }}(4 / 3) \pi \mathrm{n}_{\text {ice }}\right)\right]^{1 / 3}$.

The IWC is assumed to be $\operatorname{IWC}=\rho \max \left(0,\left[\mathrm{H}_{2} \mathrm{O}\right]-\left[\mathrm{H}_{2} \mathrm{O}_{\text {ice }}\right]\right)$,

5 with $\mathrm{H}_{2} \mathrm{O}$ molar mixing ratio $\left[\mathrm{H}_{2} \mathrm{O}\right]$ and the saturation ice water mixing ratio $\left[\mathrm{H}_{2} \mathrm{O}_{\text {ice }}\right]$ for given dilution, temperature and pressure, see Section 4.1.2.

These equations allow computing the optical depth $\tau$ and the particle size $r$ as function of time for the Geophysica, under the stratospheric conditions as defined in Table 2.

We evaluate the model equations for Geophysica conditions ( $\mathrm{span} \mathrm{s}=38.4 \mathrm{~m}$, fuel consumption $\mathrm{m}_{\mathrm{F}}=1 \mathrm{~g} \mathrm{~m}^{-1}$ ), wake

10 vortex parameters $\left(\mathrm{w}_{0}=1.34 \mathrm{~m} \mathrm{~s}^{-1}, \mathrm{t}_{\text {wake }}=132 \mathrm{~s}\right)$, shear $\mathrm{S}=0.006 \mathrm{~s}^{-1}$, reduced dilution $\mathrm{N}_{\text {dil }}(\mathrm{t})=0.25 \times 7000\left(\mathrm{t} / \mathrm{t}_{\text {dil }}\right)^{0.8}, \mathrm{t}_{\text {dil }}=1 \mathrm{~s}$, and pressure, temperature, and ambient humidity as listed in Table 2.

Figure S10 shows the change of particle size, particle number concentration and optical depth with time. It shows that the lowest contrail (2) is better and longer visible than the other ones ( 0 and 1) and that a contrail with low ice particle emission index $\mathrm{PEI}_{\text {ice }}=10^{12} \mathrm{~kg}^{-1}$ may have higher optical depth than a contrail with higher value of $\mathrm{PEI}_{\text {ice }}=2 \times 10^{15} \mathrm{~kg}^{-1}$.

15 Figure S11 shows the change of the contrail parameters as a function of $\mathrm{PEI}_{\text {ice }}$ for the conditions of the upper contrail, Table 2. We see that we obtain reasonable particle sizes $(\mathrm{r}=0.5$ to $2 \mu \mathrm{m})$, optical depth values $\tau$ up to 0.01 , and ice particle concentrations $\left(\mathrm{n}_{\text {ice }}=0.01\right.$ to $\left.1 \mathrm{~cm}^{-3}\right)$ for $\mathrm{PEI}_{\text {ice }}$ of the order of $10^{12} \mathrm{~kg}^{-1}$. The optical depth for vertical ice water path is small, partly because of large contrail width $(2830 \mathrm{~m})$ implying low contrail depth $\mathrm{D}_{\text {eff }}=1.2 \mathrm{~m}$ for given fuel consumption and dilution. The value of $\tau$ would be larger for smaller shear, giving smaller contrail width. Values of $\tau$ below 0.03 are often classified as subvisible. However, even thin contrails are still visible in clear air if seen in a direction near to the sun, because ice is scattering light mainly in forward directions. Otherwise, such thin contrails may be visible if observed slantwise. 



Figure S10. Particle size $r$ and optical depth $\tau$ versus time in the plume (age) for the three contrail formation-conditions as given in Table 2, for two values of the effective apparent ice particle emission index $\mathrm{PEI}_{\mathrm{ice}}$, for 0.25 reduced dilution $\mathrm{N}_{\mathrm{dil}}$, for 5 shear $0.006 \mathrm{~s}^{-1}$, and for wake vortex parameters as specified in Section 2.

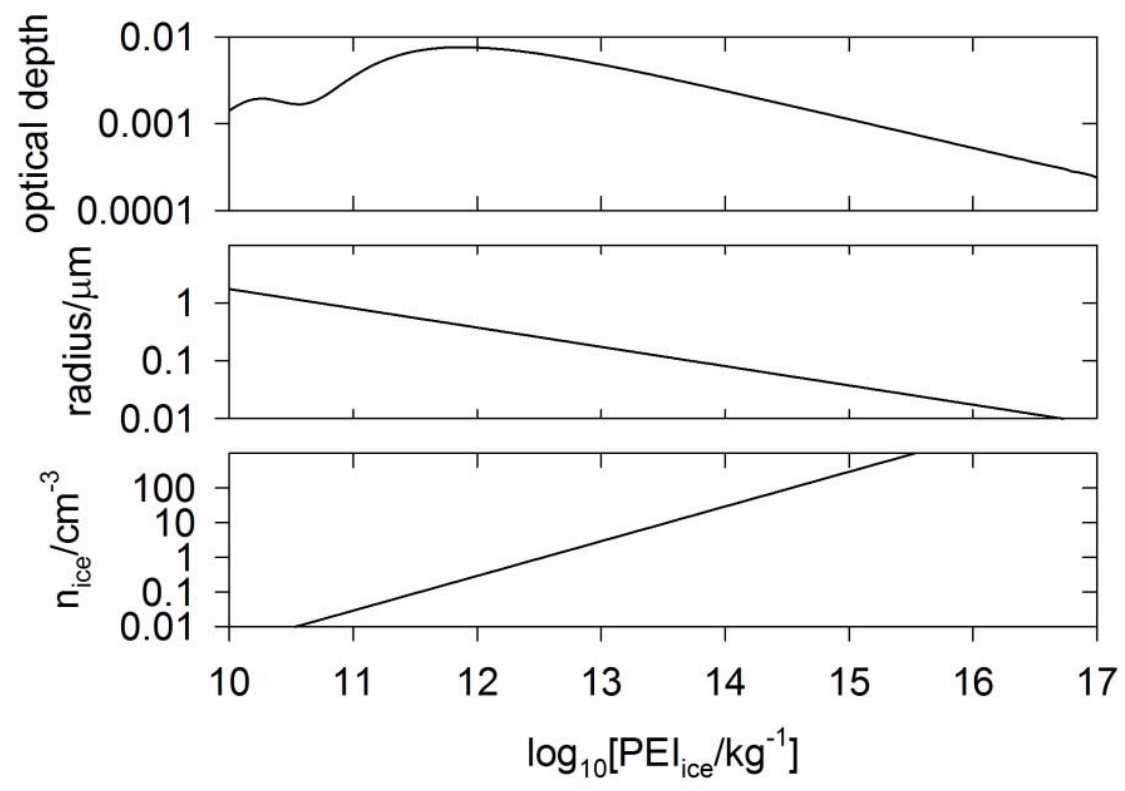

Figure S11. Optical depth $\tau$, particle radius $r$ and ice number concentration $n_{\text {ice }}$ versus decimal logarithm of the apparent ice particle emission index $\mathrm{PEI}_{\text {ice }}$ per $\mathrm{kg}$ of fuel, for conditions of the upper contrail in Table 2, and a plume age of $1000 \mathrm{~s}$. 
From the same equations, we may eliminate $\mathrm{n}_{\text {ice }}$, and obtain the well-known equation $\tau=(3 / 4)\left(\mathrm{IWC} \mathrm{D} \mathrm{Deff}_{\mathrm{ice}}\right) \mathrm{Q}_{\mathrm{ext}} / \mathrm{r}$.

Hence for fixed ice water path, IWC $D_{\text {eff }} \tau$ scales with $\mathrm{Q}_{\text {ext }} / \mathrm{r}$. Figure $\mathrm{S} 12$ shows $\mathrm{Q}_{\mathrm{ext}} / \mathrm{r}$ as a function of $\mathrm{r}$ for ice. We see, this

5 function and hence $\tau$ is maximum for $r=0.414 \mu \mathrm{m}$. This is the reason why a contrail is visible only for a certain range of ice particle sizes and effective emission indices. Related ideas were discussed earlier (Schumann, 1996).

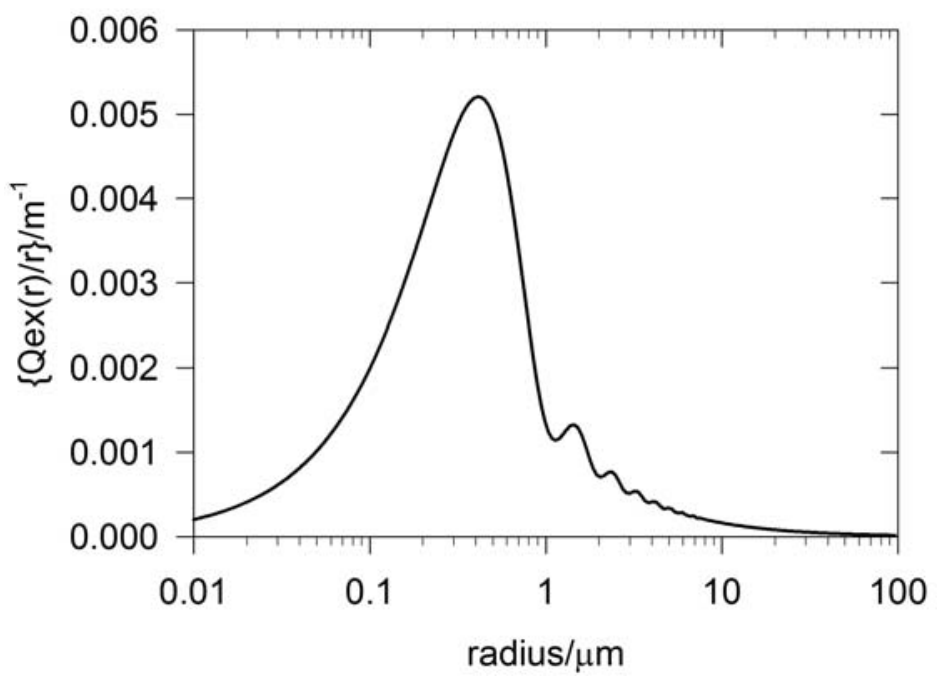

Figure S12. Function $\mathrm{Q}_{\mathrm{ext}}(\mathrm{r}) / \mathrm{r}$ for ice spheres. The maximum of 0.00521 occurs at $\mathrm{r}=0.414 \mu \mathrm{m}$. This function is controlling 10 the optical depth $\tau$ of a contrail for fixed IWC, ice bulk density $\rho_{\text {ice, }}$, and effective geometrical depth $\mathrm{D}_{\text {eff. }}$ 
Jeßberger, P., Voigt, C., Schumann, U., Sölch, I., Schlager, H., Kaufmann, S., Petzold, A., Schäuble, D., and Gayet, J.-F.: Aircraft type influence on contrail properties, Atmos. Chem. Phys., 13, 11965-11984, DOI: 10.5194/acp-13-119652013, 2013.

Lewellen, D. C.: Persistent contrails and contrail cirrus. Part II: Full lifetime behavior, J. Atmos. Sci., 71, 4420-4438, DOI: 10.1175/JAS-D-13-0317.1, 2014.

Nielsen, J. K., Larsen, N., Cairo, F., Donfrancesco, G. D., Rosen, J. M., Durry, G., Held, G., and Pommereau, J. P.: Solid particles in the tropical lowest stratosphere, Atmos. Chem. Phys., 7, 685-695, www.atmos-chem-phys.net/7/685/2007/, 2007.

Paoli, R., and Shariff, K.: Contrail modeling and simulation, Annu. Rev. Fluid Mech., 48, 393-427, doi: 10.1146/annurevfluid-010814-013619, 2016.

Schumann, U.: On conditions for contrail formation from aircraft exhausts, Meteorol. Z., 5, 4-23, 1996.

15 Schumann, U.: A contrail cirrus prediction model, Geosci. Model Dev., 5, 543-580, doi: 10.5194/gmd-5-543-2012, 2012.

Schumann, U., and Heymsfield, A.: On the lifecycle of individual contrails and contrail cirrus, Meteor. Monogr., 58, doi:10.1175/AMSMONOGRAPHS-D-16-0005.1, 2017.

Schumann, U., Mayer, B., Gierens, K., Unterstrasser, S., Jessberger, P., Petzold, A., Voigt, C., and Gayet, J.-F.: Effective radius of ice particles in cirrus and contrails, J. Atmos. Sci., 68, 300-321, DOI: 10.1175/2010JAS3562.1, 2011.

Schumann, U., Baumann, R., Baumgardner, D., Bedka, S. T., Duda, D. P., Freudenthaler, V., Gayet, J.-F., Heymsfield, A. J., Minnis, P., Quante, M., Raschke, E., Schlager, H., Vázquez-Navarro, M., Voigt, C., and Wang, Z.: Properties of individual contrails: A compilation of observations and some comparisons, Atmos. Chem. Phys., 17, 403-438, doi:10.5194/acp-17-403-2017, 2017.

Sumińska-Ebersoldt, O., Lehmann, R., Wegner, T., Grooß, J.-U., Hösen, E., Weigel, R., Frey, W., Griessbach, S., Mitev, V., Emde, C., Volk, C. M., Borrmann, S., Rex, M., Stroh, F., and von Hobe, M.: ClOOCl photolysis at high solar zenith angles: analysis of the RECONCILE self-match flight, Atmos. Chem. Phys., 12, 1353-1365, doi:10.5194/acp-12-13532012, 2012.

Weigel, R., Hermann, M., Curtius, J., Voigt, C., Walter, S., Böttger, T., Lepukhov, B., Belyaev, G., and Borrmann, S.: Experimental characterization of the COndensation PArticle counting System for high altitude aircraft-borne application, Atmos. Meas. Tech., 2, 243-258, doi:10.5194/amt-2-243-2009, 2009. 